\title{
Principal component regression of the morphostructural traits of West African dwarf sheep
}

Bello-ibiyemi, A. A., M. Wheto', A. S. Adenaike' ${ }^{1}$ J. S. Decampos, D.O. Ogunlakin, M. Atunnise, S. Shola and Ikeobi, C.O.N.'

Department of Animal Breeding and Genetics, College of Animal Science and Livestock Production, Federal University of Agriculture Abeokuta, P. M.B. 2240, Ogun State, Nigeria

Corresponding author: Ballomi13@gmail.com

\begin{abstract}
Evaluation of body weight and seven morphostructural traits (body length, wither's height, rump height, fore cannon bone length, chest depth, hip width and hearth girth) of 200 West African dwarf (WAD) sheep of age range 0-1, 1-2, 2-3 and 3-4 was used in determining age and sex effects using General linear model procedure. The sheep were traditionally managed in flocks of southern and north central Nigeria. Interdependence magnitude (redundancy) was estimated to be positive and significant through pearson's correlation estimates between body weight and linear body dimensions $(r=0.04-0.81 ; P<0.01)$. Among the linear type traits, highest correlation was observed between body weight and hearth girth in males ( $r=$ $0.85)$ and females $(r=0.81)$ respectively. Multicollinearity contrast at variance inflation factor (VIF) threshold 3.0 was found to be most associated with rump height, hearth girth and body length; with low tolerance modules. Collinearity effects were further orchestrated with computations of eigen values, condition indexes and variance proportions. The component solution through VARIMAX orthogonal rotation generated one principal component for WAD sheep of age range 0-2 years, and two principal components for age range 2-4 years. The principal component based on regression models revealed, body weight was best predicted from heart girth, and combination of rump height and wither's height measurements.
\end{abstract}

Keywords: Principal component analysis, Morphostructural traits, West African Dwarf sheep.

\section{Introduction}

Livestock contribute immensely to the growth and development of any nation. Its supplies contribute to adequate protein consumption, mainly estimated at 27.9 percent worldwide and 47.8 in developed countries (FAOSTAT, 2011). In Nigeria, the population of sheep as a livestock resource is put at 22.1 million (Lawal-Adebowale, 2012).

Sheep and goats have been raised in areas in which incomes of farmers are relatively low (Kurniantoet al., 2013). FAO (2012) has reported that population's production environment needs a comprehensive description to understand special adaptations of the animals.

Phenotypic characteristics are important in breed identification and classification (Adejoro and Salako, 2013). Body weight and body measurements are essential parameters to describe growth; body measurements can describe completely an individual or a population (Salako, 2006b). Frontier techniques that have traditionally been used to extensively explain relationships of morphometric traits recently are the multivariate techniques. Principal components regression (PCR) is a multivariate method used in resolving 


\section{Principal component regression of the morphostructural traits of West African dwarf sheep}

multicollinearity and results in estimation and prediction better than ordinary least squares when appropriately used (Myers, 1986). PCR is a technique of analysis that is based on principal component analysis (Kendall, 1968; Cook, 2007). When multicollinearity occurs, least squares estimates are unbiased, but their variances are large so they may be far from the true values. Therefore, $P C R$ analyses multiple regression data that suffer from multicollinearity regardless of addition of a degree of bias to the regression estimates, and reduces the standard errors to give a net effect that will be to obtain more reliable estimate values (Hoe and Kim, 2004). Multiple regression and discriminant analyses have been reported to be affected by multicollinearity hence; reports have shown that the approach to eliminate multicollinearity is to adopt principal component analysis (Mendes, 2009).

An assessment of the morphometric relationship among livestock breeds has been achieved using multivariate statistical methodology such as principal component analysis (PCA) in goats (Yakubu et al., 2009; Yakubu, 2011; Birteeb and Lomo, 2015) and sheep breeds such as Yankassa (Yakubu, 2013), Uda (Salako, 2006b, Yakubu et al., 2011) but there has not been report of it on WAD sheep in the South Western region of Nigeria except for few methodologies such as discriminant analysis and multiple regressions which have mostly been reported. However, West African Dwarf Sheep breed is prevalent in the south western part in large proportion where they are managed under extensive management system (Sowande, 2007). PCA is one of the multivariate analysis techniques usually used for correlation analysis, data reduction and also efficiency assessment (Rossi and Thomas, 2001).

By contrast, simple regression analysis would yield different equations and models to most probably predict body weight in different breeds, same may not be applicable to all breed type (Adeyinka et al., 2006). Basically, PCA finds weights according to the Eigen value and Eigen vectors of a specific matrix that describes the covariance or correlation between variables. This analysis refines an original group variable into another variable (Ogah et al., 2009); using an orthogonal transformation when viewed from its most informative viewpoint.

The West African Dwarf (WAD) sheep breed is characterized with morphometric indicators of dwarfism which undermines its utility as a good meat type breed mainly because it is small bodied and short (Adejoro and Salako, 2013). However, it has been identified to be of good genetic resource, trypanotolerant and adaptable to the humid tropics (Sowande, 2007). The West African Dwarf Sheep are reared extensively by small holder farmers in south Western Nigeria (Bemji et al., 2012).

\section{Materials and methods}

The data for this study were generated from West African dwarf sheep traditionally managed in parts of southern and north central Nigeria. A total of 200 sheep was sampled to obtain measurements for the study. On spot sampling procedure was used in obtaining measurements. The morphostructural parameters measured on each of the experimental animal included body length (BL), wither's height (WH), rump height $(\mathrm{RH})$, fore cannon bone length (FCBL), chest depth (CD), hip width (HW) and hearth girth (HG).

Data generated was analyzed using principal component analysis (PCA) method of the multivariate statistical analysis employing the factor programme of the Statistical Package and Solution 


\section{Bello-ibiyemi, Wheto, Adenaike, Decampos, Ogunlakin, Atunnise, Shola and Ikeobi}

Software SPSS (Version 16.0). Means, standard deviation and pearson's correlation coefficients were obtained. Components were calculated using all of the variance of the manifest variables, and all of that variance appears in the solution (Ford et al., 1986).

Pearson's coefficient of correlation (r) among the various body measurements was estimated. The correlation matrix was used to relate redundancy among the parameter estimates (so also, the tolerance levels of the regression model), from which standardized form of the original data was obtained and consequently used in the principal component analysis solution. The correlation matrix served as the standardized data source for the PCA generated and was inspected for sampling adequacy (Kaiser-Meyer-Okin Test) and sphericity (Batttlet's Test).

Anti-image correlations, Kaiser-MeyerOlkin measures of sample adequacy and Bartlett's test of sphericity were used to test the validity of the data sets. The general model form for the computation of scores on the components extracted (created) in the principal component analysis is given below:

$\mathrm{Yp}=\mathrm{b} p 1(\mathrm{X} 1)+\mathrm{bp} 2(\mathrm{X} 2)+\ldots \mathrm{bpp}(\mathrm{Xp})$
Where:

Yp $=$ the subject's score on principal component (component extracted)

$\mathrm{bp} 1=$ the regression coefficient for observed variable $p$, as used in creating principal component extracted $\mathrm{Xp}=$ the subject's score on observed variable $p$.

The multiple linear regression model used following stepwise procedure was:

$Y=\alpha+\beta_{1} X_{1}+\beta_{2} X_{2}+\beta_{3} X_{3}+\beta_{4} X_{4}+\beta_{5} X_{5}+$ $\beta_{6} \mathrm{X}_{6}+\beta_{7} \mathrm{X}_{7}+\mathrm{e}$

Where:

$\mathrm{Y}=$ dependent variable (body weight)

$\alpha=$ intercept

$\beta$ 's $=$ regression coefficients

$\mathrm{X}^{\prime} \mathrm{s}=$ predictor variables $(\mathrm{BL}, \mathrm{WH}, \mathrm{RH}$, FCBL, CD, HW, HG)

$\mathrm{e}=$ error term

The principal component based regression model used to predict body weight from principal component factor scores is given as

$\mathrm{BW}=\mathrm{a}+\mathrm{biPCi}+$ $+\mathrm{bkPCk}$

Where

$\mathrm{BW}=$ body weight

$\mathrm{a}=$ regression intercept

$b i=i^{\text {th }}$ partial regression coefficient of the

$i^{\text {th }}$ linear body measurement,

$\mathrm{PCi}=\mathrm{i}^{\text {th }}$ or $\mathrm{k}^{\text {th }}$ principal component $(\mathrm{PC})$.

\section{Results}

Table 1: Descriptive statistics of body weight and morphostructural body traits of West African Dwarf sheep based on age range

\begin{tabular}{ccccc}
\multicolumn{4}{l}{ Dwarf sheep based on age range } \\
\hline Age 0-1 & Age 1-2 & Age 2-3 & Age 3-4 \\
Source & Mean \pm SD & Mean \pm SD & Mean \pm SD & Mean \pm SD
\end{tabular}

\begin{tabular}{lllll}
\hline BW & $6.90 \pm 2.10$ & $11.13 \pm 3.68$ & $16.70 \pm 4.35$ & $19.75 \pm 4.09$ \\
BL & $47.57 \pm 7.37$ & $54.85 \pm 5.37$ & $60.78 \pm 5.96$ & $64.31 \pm 6.13$ \\
WH & $35.03 \pm 5.08$ & $39.23 \pm 3.34$ & $41.85 \pm 4.81$ & $44.05 \pm 3.01$ \\
RH & $36.62 \pm 5.18$ & $41.79 \pm 4.42$ & $44.68 \pm 3.69$ & $45.90 \pm 4.15$ \\
FCLB & $8.52 \pm 1.36$ & $9.26 \pm 1.68$ & $9.56 \pm 1.41$ & $9.36 \pm 1.28$ \\
CD & $18.39 \pm 3.44$ & $21.29 \pm 4.71$ & $23.81 \pm 4.32$ & $24.79 \pm 2.54$ \\
HW & $8.19 \pm 1.47$ & $9.25 \pm 1.41$ & $10.89 \pm 5.57$ & $11.98 \pm 1.73$ \\
HG & $45.06 \pm 4.13$ & $51.57 \pm 5.18$ & $57.83 \pm 5.57$ & $60.55 \pm 6.70$ \\
\hline
\end{tabular}

SD - standard deviation, BL - body length, WH - wither's height, RH - rump height, FCBL - fore cannon bone length, CD - chest depth, HW - hip width and HG - hearth girth. 
Principal component regression of the morphostructural traits of West African dwarf sheep Table 2: Correlation coefficients of body weight and morphostructural body traits of West African Dwarf sheep of both sexes

\begin{tabular}{lllllllll}
\hline Trait & BW & BL & WH & RH & FCBL & CD & HW & HG \\
\hline BW & 1.000 & & & & & & \\
BL & .732 & 1.000 & & & & & \\
WH & .628 & .675 & 1.000 & & & & \\
RH & .672 & .732 & .763 & 1.000 & & & \\
FCBL & .276 & .222 & .384 & .377 & 1.000 & & \\
CD & .575 & .477 & .568 & .570 & .342 & 1.000 & & \\
HW & .597 & .583 & .474 & .528 & .040 & .357 & 1.000 & \\
HG & .811 & .733 & .653 & .703 & .371 & .613 & .582 & 1.000 \\
\hline
\end{tabular}

BL - body length, WH - wither's height, RH - rump height, FCBL - fore cannon bone length, CD chest depth, HW - hip width and HG - hearth girth.

Table 3: Collinearity statistics for the linear body measurements of West African Dwarf sheep

\begin{tabular}{lll}
\hline Trait & Tolerance & VIF \\
\hline BL & .332 & 3.012 \\
WH & .357 & 2.802 \\
RH & .298 & 3.360 \\
FCLB & .733 & 1.365 \\
CD & .558 & 1.792 \\
HW & .564 & 1.773 \\
HG & .315 & 3.175
\end{tabular}

BL - body length, WH - wither's height, RH - rump height, FCBL - fore cannon bone length, CD - chest depth, HW - hip width and HG - hearth girth.

\begin{tabular}{|c|c|c|c|c|c|c|c|c|c|c|}
\hline \multirow[b]{2}{*}{ Component } & \multicolumn{8}{|c|}{ Variance proportions } & \multirow[b]{2}{*}{ HW } & \multirow[b]{2}{*}{ HG } \\
\hline & Eigenvalue & CI & $\mathrm{C}$ & BL & WH & RH & FCBL & CD & & \\
\hline 1 & 7.901 & 1.000 & .00 & .00 & .00 & .00 & .00 & .00 & .00 & .00 \\
\hline 2 & .035 & 15.022 & .01 & .01 & .00 & .00 & .20 & .01 & .36 & .00 \\
\hline 3 & .025 & 17.759 & .07 & .00 & .00 & .00 & .05 & .73 & .02 & .00 \\
\hline 4 & .013 & 24.425 & .00 & .14 & .04 & .03 & .37 & .04 & .55 & .00 \\
\hline 5 & .010 & 27.857 & .84 & .06 & .00 & .00 & .26 & .10 & .00 & .04 \\
\hline 6 & .007 & 33.754 & .08 & .09 & .38 & .08 & .00 & .00 & .04 & .33 \\
\hline 7 & .005 & 40.465 & .00 & .62 & .14 & .00 & .11 & .11 & .02 & .62 \\
\hline 8 & .004 & 44.622 & .00 & .08 & .44 & .88 & .01 & .00 & .00 & .00 \\
\hline
\end{tabular}


Bello-ibiyemi, Wheto, Adenaike, Decampos, Ogunlakin, Atunnise, Shola and Ikeobi

Table 5: Rotated component matrix for the age groups

\begin{tabular}{lllllll}
\hline & \multicolumn{3}{c}{ Age group 0 - 2 } & & \multicolumn{3}{c}{ Age group 2 - 4 } \\
\cline { 2 - 3 } \cline { 5 - 6 } Trait & PC 1 & Communality & & PC 1 & PC 2 & Communality \\
\hline BL & .775 & .601 & .693 & .353 & .605 \\
WH & .851 & .725 & .770 & -.178 & .625 \\
RH & .882 & .777 & .798 & -.051 & .639 \\
FCBL & .484 & .234 & & .394 & -.774 & .755 \\
CD & .554 & .307 & .288 & .722 & -.177 & .552 \\
HW & .537 & .666 & & .279 & .843 & .788 \\
HG & .816 & & .748 & .089 & .567 \\
Eigenvalue & 4.00 & & 3.02 & 21.53 & \\
$\%$ Variance & 51.41 & & & & & \\
\hline
\end{tabular}

PC - principal component, BL - body length, WH - wither's height, RH - rump height FCBL - fore cannon bone length, CD - chest depth, HW - hip width and HG - hearth girth

Table 6: Component score co-efficient for body weight estimation on age group basis

\begin{tabular}{lcccc}
\hline \multirow{2}{*}{ Trait } & \multicolumn{2}{c}{ Age group 0-2 } & & \multicolumn{2}{c}{ Age group 2-4 } \\
\cline { 2 - 3 } BL & PC 1 & & PC 1 & PC 2 \\
WH & .22 & .23 & .23 \\
RH & .24 & .25 & .12 \\
FCBL & .25 & .26 & .03 \\
CD & .13 & .13 & -.52 \\
HW & .15 & .24 & -.12 \\
HG & .15 & .09 & .56 \\
\hline
\end{tabular}

PC - principal component, BL - body length, WH - wither's height, RH - rump height FCBL - fore cannon bone length, CD - chest depth, HW - hip width and HG - hearth girth. 


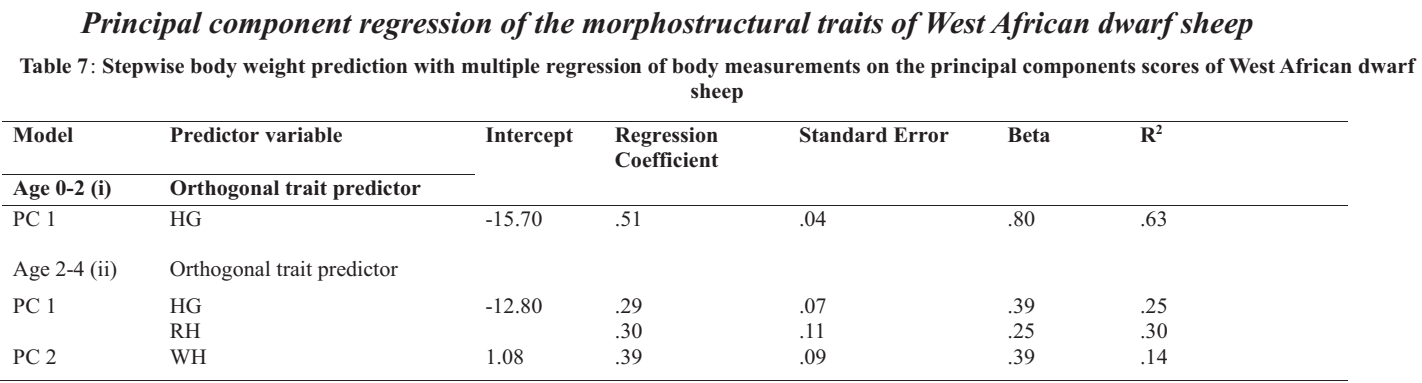

PC - principal component, BL - body length, WH - wither's height, RH - rump height, FCBL - fore cannon bone length, CD - chest depth, HW hip width and HG - hearth girth.

\section{Discussion}

The data generated from this study was evaluated for correlation coefficients of body weight and body linear traits revealed by the pearson's coefficient of correlation modules. The high magnitudes suggest there was interplay of sexual dimorphism with regards to both sheep sexes. This result is in congruence with observations of Yakubu (2010), that sexual dimorphism observed in Yankassa sheep could be as a result of the usual inter-sex differential hormonal action, which invariably leads to differential growth rates in maleand female animals i.e. non release of androgen (which is known to have growth and weight stimulating effects) in male animals until the testes is well developed (Frandson and Elmer, 1981).

However, males had highest magnitudes of correlation associated with body weight and heart girth and lowest with height at withers and fore cannon bone length. Hearth girth showed highest levels of correlation with body weight in West African Dwarf sheep sexes. These findings are in consonance with reports of Salako and Ngere (2002), Salako (2006) and Yakubu (2010). If genes influencing the configuration of an animal are of common action and not local, the formation of one part is found narrowly correlated with the formation of the other (Lener and Donald, 1996).

Variance Inflation Factor (VIF) and Tolerance $(\mathrm{T})$ estimates explain the nature of interdependence, redundancy levels of body weight and body morphostructural traits as multicollinear. Since VIF has a lower bound of 1 but no upper bound, authorities differ on how high VIF has to be to constitute a problem (Paul, 2012). Necessarily, there can be concerns when VIF is greater than 2.50 (Paul, 2012). Tolerance modules were low for reasonably high VIF values. As reported by Belsleyet al. (1980), a bivariate correlation matrix of explanatory variables might not be reliable enough to identify collinearity; this informs the employment of VIF, which represents the increase in variance due to redundant correlation between predictors and hence, severity of multicollinearity with regards to West African Dwarf sheep is low.

Johnson and Wichern (2002) describedprincipal components as linear combination of original variables and are estimated such that the first principal component explains the largest percentage of the total phenotypic variance. The principal components help in elimination of redundancies from sets of interdependent variables, extract and identify covariant variable sets that are statistically unrelated (Nugent and Notter, 1991; Shahinet al., 1995; Yakubuet al., 2011).

It was observed from the rotated component matrix for the age groups that rump height, wither's height, heart girth, chest depth, hip width and body length were most associated with principal component 1 for $0-2$ age range. Rump height, wither's height, heart 
girth, chest depth and body length were most associated component scores with principal component 1 of age range 2-4, while hip width is distinguished on principal component 2 for age range between 2-4. The first component extracted, been characterized by high positive loadings appears to be the index of general body size (Yakubu, 2013). It can be deduced therefore, that rump height, wither's height, heart girth, chest depth and body length are the morphological traits explaining the generalized percentage variance.

This finding conforms to the findings of Birteebet al., (2013), on sheep, that five linear body traits including chest depth, height at withers, rump height, body length and pin-bone width lied on the first principal component and hence, the factor can be orchestrated and considered as a generalized index of size conformation in sheep.

More informatively, the magnitude of values of the elements clustered in each extracted principal component matrix is likely implicative that the genomic sites for their genetic control is common (Salako, 2006a). In other words, pleiotropy is possibly substantiated.

Hip width on the other hand, been characteristic of principal component 2 of age range 2-4 gives a clear picture that it is possibly controlled by a variant source i.e. different gene. Yakubu (2013) reported that subsequent factors mutually orthogonal to the first and presented patterns of variation independent of general size, informs collinearity breakage, common in the analysis of closely related conformation traits.

Hip width (0.54) on principal component 1 , of age range $0-2$, shows that when age increased, it differentiated from the possibly associated traits on principal component 1 (0.28) and strengthened (0.84) on principal component 2 of age range 2-4. This further elucidates that time taken to reach maturity or environmental component could affect the timely pronouncement of a trait in an animal and its association with bone (Salako, 2006a). In reports on Yankassa sheep breed, measurement of hip width was negatively correlated with measure of muscularity and hence, body weight (Afolayan, 2006).

Coefficient of determination $\left(\mathrm{R}^{2}\right)$ values computed for the body measurements was high for hearth girth. With respect to age range, of body linear traits, girth was most related trait to body weight (Afolayan, 2006). Hearth girth was found to predict body weight with higher precision and better in estimating live weight. Hearth girth alone could be preferable to combinations with other measurements in body weight prediction because of the difficulty of the proper animal restraint during measurement in cattle, thus reducing the practical usefulness of using other body measurements (Berge, 1977). Also, Yakubu (2010) has reported that heart girth has greatest direct effect on body weight.

Heart girth (HG), rump width $(\mathrm{RH})$ and withers height $(\mathrm{WH})$ depicted the highest relationship to live weight in linear and allometric models compared to other body measurements. Based on stepwise elimination procedure, $\mathrm{HG}, \mathrm{HL}$ and $\mathrm{WH}$ were better in predicting live weight in multiple linear regression models. Heart girth measurements are usually affected by gut fill andare highly variable (Salako, 2006a).

Fajemilehin and Salako (2008) reported that, body weights could be predicted accurately from hearth girth (HG), wither's height (WH) and rump height (RH) among other traits in WAD goats. The result of the 
Principal component regression of the morphostructural traits of West African dwarf sheep

multiple regressionanalyses in cattle indicated that the addition of other measurements to chest girth would result in significant improvements in accuracy of prediction of live weight estimation (Afolayan, 2006).

\section{References}

Adejoro, F. A. and Salako, A. E. 2013. Morphometrical Indices of Dwarfism in the West African Dwarf Sheep as Compared to the Yankassa Sheep. International Journal of Agriculture and Biosciences 2(2): 72-75.

Afolayan, R. A., Adeyinka, I. A and Lakpini, C. A. M. 2006. The estimation of live weight from body measurements in Yankasa sheep. Czech Journal of Animal Science, 51(8): 343-348.

Belsley, D.A., Kuh, E. and Welsch, R. E. 1980. Regression diagnostics: Identifying influential $d$ a $t \quad a$ sources of collinearity. New York: John Wiley and Sons.

Bemji, M. M., Ogunjimi, A. A., Ode, A. J., Okediji, S. R., Akinwunmi, A. T., Sanyaolu, T. O., Salawudeen, B. S., Kelani, B. A., Ogunsola, A. O., Agunbiade, M. O., Adenaike, A. S. and Ogudiyi, A. I. 2012. Prevalence of Coat Colour Phenotypes in West African Dwarf Sheep reared by Small Holder Farmers in South Western Nigeria. American journal of experiment agriculture, 2(4): 587596.

Berge, S. 1977. Estimation of weight and increase in weight by means of the chest girth in Norwegian red cattle at the Agricultural University at Norway. Acta Agric. Scand., 27: 65-66.
Birteeb, P. T., Peters, S. O. and Ozoje, M. O. 2013. Factor analysis of biometric traits of Djallonke sheep in Northern Ghana. Journal of Animal Science, 91: 295.

Birteeb, P. T. and Lomo, R. 2015. Phenotypic characterization and weight estimation from linear body traits of West African Dwarf goats reared in the transitional zone of Ghana. Livestock Research for Rural Development. Volume 27, Article\#175. Retrieved September $27, \quad 2016, \quad$ f r o m http://www.lrrd.org/lrrd27/9/birt2 7175.htm

Cook, R. D. 2007: Fisher lecture: Dimension reduction in regression. Statistical Science, 22(1): $1-26$.

Fajemilehin, S. O. K. and Salako, A. E. 2008. Body measurement characteristics of the West African Dwarf (WAD) Goat in deciduous forest zone of Southwestern Nigeria. African Journal of Biotechnology, 7(14): 2521-2526.

Food and Agriculture Organization (FAO) 2012. Phenotypic characterization of animal genetic resources. FAO Animal Production and Health Guidelines No. 11. Rome.

FAOSTAT 2011. FAOSTAT Database on A $\begin{array}{lllllllllllllllll} & \mathrm{r} & \mathrm{i} & \mathrm{c} & \mathrm{u} & \mathrm{l} & \mathrm{t} & \mathrm{u} & \mathrm{r} & \mathrm{e}\end{array}$. http://www.faostat.fao.org. Accessed on September 18, 2012.

Ford, J. K., MacCallum, R. C. and Tait, M. 1986. The Application of Exploratory Factor-Analysis in Applied- Psychology - a CriticalReview and Analysis. Personnel 
Psychology, 39(2): 291-314.

Frandson, R. D. and Elmer, H. W. 1981. Anatomy of the male Reproductive system. Lea and Febiger, Philadephia pp 56.

Hoe, J. S. and Kim, D. S. 2004: A new method of ozone forecasting using fuzzy expert and neural network systems. Science of the Total Environment325:221-237

Johnson, R. A. and Wichern, D. W. 2002. Applied Multivariate Statistical Analysis. Prentice Hall New Jersey.

Kendall, M. G. 1968. A course in multivariate analysis. New York pp 185.

Kurnianto, E., Sutopo, E., Purbowati, E. T., Setiatin, D. S. and Permat a s ri, T. 2013 . Multivariate Analysis of Morphological Traits of Local Goats in Central Java, IndonesiaIranian Journal of Applied Animal Science, 3(2): 361367.

Lawal-Adebowale, O. A. 2012. Dynamics of Ruminant Livestock Management in the Context of the Nigerian Agricultural System. Livestock Production. 1:61-80.

Lener, I. M. and Donald, H. P. 1996. Modern Developments in Animal Breeding. Academic Press, London, pp 295.

Mendes, M. 2009. Multiple linear regression models based on principal component scores to predict slaughter weight of b r o i l e r s. Archive Gefligelkünde73(2): 139-144.

Morrison, D. F. 1976. Multivariate statistical methods. McGraw-Hill Company, New York, pp 325-346.

Myers, R. H. 1986. Classical and modern regression with applications. Duxbury Press. Boston. pp 359.

Nugent, R. A. and Notter, D. R. 1991. Body measurements of crossbred calves sired by Simmental bulls divergently selected for progeny first-calf calving ease in relation to birth weight. Journal of Animal Science, 69: 2422-2433.

Ogah, D. M. Alaga, A. A. and Momoh, M. O. 2009. Principal Component FactorAnalysis of $\quad \mathrm{T} \quad \mathrm{h} \quad \mathrm{e}$ Morphostructural traits of Muscovy Ducks. International Journal of poultry science, 8(11): 1100-1103.

Paul, A. 2012. Statistical Horizons. Http://www.statisticalhorizons.co $\mathrm{m}$. A c c e s s e d o n 30 December, 2013.

Robert, M. O. 2007. A Caution Regarding Rules of Thumb for Variance Inflation Factors. International Journal of methodology, 41(5): 673-690.

Rossi, F. and Thomas, A. A. 2001. Analysis of the beverage data Using Cluster Analysis Rotated Principal Components Analysis and LOESS curves. // Food Quality and Preference. 12, 5 7(2001), pp. 437-445.

Salako, A. E. and Ngere, L. O. 2002: Application of multifactorial discriminant analysis in the Morphometric structural differentiation of the WAD and Yankasa sheep in the humid southwest Nigeria. Nigerian Journal of Animal Production, 29(2): 163-167.

Salako, A. E. 2006a. Application of Morphological indices in the assessment of type and function in sheep. International Journal of 
Principal component regression of the morphostructural traits of West African dwarf sheep

Morphology, 24(1): 8-13.

Salako, A. E. 2006b: Principal component factor analysis of the morphostructure of the Immature Uda sheep. International Journal of Morphology 24: 571-574.

Shahin, K. A. Soliman, A. M. and Moukhtar, A. E. 1995. Sources of shared variability for the Egyptian cattle body shape (conformation). Indian Journal of Animal Science, 65: 759764.

Sowande, O. S. 2007. Body measurement of West African Dwarf sheep as parameter for estimation of live weight. Tropical animal health and Production 4(6): 443-449.

Yakubu, A. 2009. Fixing collinearity instability in the estimation of body weight from morpho-biometrical traits of West African Dwarf goats, Trakia Journal of Sciences, 7: 6166.

Yakubu, A., Kuje, D. and Okpetu, M. 2009. Principal components as measures of size and shape in Nigerian indigenous chicken. Thai Journal of Agricultural Science, 42(3): 167- 176.

Yakubu, A. 2010. Path Coefficient and Path Analysis of Body Weight and Biometric Traits in Yankasa Lambs.Slovak Journal of Animal Science, 43(1): 17-25.
Yakubu, A. and Akinyemi, M. O. 2010. An evaluation of sexual size dimorphism in Uda sheep using multifactorial discriminant

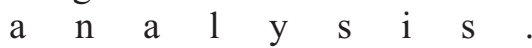
ActaAgriculturaeScandinavica, 60: 74-78.

Yakubu, A. and Ibrahim, 2011, I. A. Multivariate analysis of morphostructural characteristics in Nigerian indigenous sheep. Italian Journal of Animal Science, 10(2): 83-86.

Yakubu, A., Salako, A. E. and Immumorin, I. G. 2011. Comparative multivariate analysis ofbiometric traits of West African Dwarf and Red Sokoto goats. Tropical Animal Health and Production 43(3): 561-566.

Yakubu, A. 2013. Principal component analysis of the conformation traits of Yankasa sheep. Biotechnology in Animal Husbandry, 29(1): 6574.

Received: $13^{\text {th }}$ November, 2016 Accepted: $28^{\text {th }}$ January, 2017 